\title{
Risk Factors and Outcome of Obstructed Labour at a tertiary care Hospital
}

\author{
Islam JA ${ }^{1}$, Ara $\mathrm{G}^{2}$, Choudhury $\mathrm{FR}^{3}$
}

\begin{abstract}
Background: Obstructed labour is one of the most common preventable cause of maternal and prenatal morbidity and mortality in developing countries. Objective: The purpose of the present study was to determine the risk factors as well as to asses the outcome of obstructed labour. Method: This cross sectional study was conducted in the Department of Gynecology \& Obstetrics at Shaheed Ziaur Rahman Medical College Hospital, Bogra during the period from January 2007 to December 2007. One hundred and five cases with features of obstructed labour were selected as per inclusion and exclusion criteria in a consecutive method. A detailed history included sociodemographic feature, obstetric history, features of obstruction, intrapartum events were recorded to detect risk factors. Condition of patients, mode of delivery, preoperative and post operative complications, maternal and fetal outcomes were recorded. Results: A total number of 3171 deliveries were conducted during this period and 132 cases of obstructed labour were found constituting an incidence of $4.2 \%$. The highest frequency was found among the unbooked, primigravid patients that were illiterate or only having primary education level. The commonest cause was cephalo-pelvic disproportion (47.5\%) followed by fetal malpostion (25.7\%) and malpresentation (24.8\%). The majority of the patients were between 25-29 years, caeserean section was the most common mode of delivery $(78.09 \%)$. Maternal morbidity due to different complication accounted for $76.19 \%$ of the case while the fetal morbidity was $51.31 \%$ of the cases. The maternal mortality was $1 \%$ and prenatal mortality was $24.76 \%$. Conclusion: In this study the incidence of obstructed labour was very high. The commonest cause was cephalo-pelvic disproportion followed by fetal malpostion and malpresentation.
\end{abstract}

Key words: Obstructed labour, cephalopelvic disproportion, prenatal morbidity

\section{Introduction}

Obstructed labour results from failure of descent of fetal presenting part in the birth canal for mechanical region, in spite of good uterine contraction and it leads to various maternal and fetal complications ${ }^{1-3}$. It is one of the most common preventable cause of maternal and prenatal morbidity and mortality in developing countries ${ }^{4-6}$. It accounts for about $8 \%$ of total maternal death in Bangladesh $^{7}$. Several studies from other developing countries found an incidence ranging from $2-8 \%$ of all hospital deliveries ${ }^{8-10}$. Its occurrence is regarded as a sign of poor level of obstetric practice in any environment because obstructed labour is due to mechanical difficulties which takes place where access to proper obstetric care might not be available or utilized.

In booked patients obstructed labour is prevented by elective caeserean section where dystocia is anticipated, and the use of partogram in labour management is early recourse to emergency caesarean section ${ }^{11-12}$. At present, most of the women in this country don't have timely access to EOC and only $5 \%$ of expected complications reach the medical facilities. This is because of three delay model that is delay in decision to take care, delay to reach the health care centre, and delay to receive adequate treatment. In Bangladesh $80 \%$ people live in rural areas, where most of the deliveries (90\%) are conducted at home ${ }^{13}$. Traditional birth attendants (TBA) conduct $63 \%$ of deliveries of which $38 \%$ are conducted by trained TBA and $25 \%$ are conducted by untrained ones ${ }^{13}$. In Bangladesh there is a high prevalence of teenage pregnancies and grand-multiparity due to early marriage ${ }^{14}$. Repeated pregnencies out side the hospital by untrained midwives leads to obstructed laboure which is a common cause of maternal mortality and morbidity ${ }^{14}$.

The incidence of obstructed labour and its complications have been minimized in the developed countries because of good nutritional status, facilities for transport and communication, wide spread health coverage and availability of trained health personnel along with optional

1. Dr. Jinnat Ara Islam, Assistant Professor, Department of Gynecology \& Obstetrics, Shaheed Suhrawardy Medical College \& Hospital, Dhaka

2. Dr. Gulshan Ara, Associate Professor, Department of Gynecology \& Obstetrics, Sir Salimullah Medical Colllege \& Mitford Hospital, Dhaka

3. Dr. Farzana Rabee Choudhury, Junior Consultant, Department of Gynecology \& Obstetrics, Shaheed Suhrawardy Medical College \& Hospital, Dhaka

\section{Correspondence}

Dr. Jinnat Ara Islam, Assistant Professor, Department of Gynecology \& Obstetrics, Shaheed Suhrawardy Medical College \& Hospital, Dhaka, Bangladesh; Email: jinnat_shsmc@yahoo.com; Cell no.: +8801711184306 
utilization of antepartum and intrapartum care ${ }^{15}$. Globally, approximately $80 \%$ of maternal deaths are due to direct obstetric complications like primary hemorrhage, sepsis, pre-eclampsia, eclampsia and obstructed labour ${ }^{16}$. Together with hemorrhage, infection, hypertensive disorder of pregnancy, obstructed labour is a major cause of prenatal and maternal mortality and morbidity in developing countries $^{17}$. More than 529000 women die every year from pregnancy related complication and more than $99 \%$ of these deaths take place in the developing countries ${ }^{18}$. The common cause of obstructed labour are cephalopelvic disproportion, malposition and malpresentation. The most important maternal morbidities are postpartum hemorrhage, wound infection, puerperal sepsis, abdominal distension, ruptured uterus as well as VVF. Fetal outcomes are still birth, asphyxia, neonatal jaundice and umblical sepsis.

The purpose of the present stady was to determine the risk factors, socio-demographic factors as well as outcome of obstructed labour. Due to poor transport facilities most of the patients were brought late in morbid state.

\section{Methodology}

This cross-sectional study was carried out from January 2007 to December 2007 in the Department of Gynecology \& Obstetrics at Shaheed Ziaur Rahman Medical College Hospital, Bogra. Shaheed Ziaur Rahman Medical College is a tertiary care hospital where cases are referred from upazilla as well as private clinics. After obtaining written informed consent patients with features of obstructed labour were enrolled consecutively in this study. Both prime and multi-gravida patients admitted with obstructed labour or developing this condition after admission were included. Patients having hypertension, convulsion or other medical diseases were excluded. A detailed history including obstetric history, socio-demographic history, any medical disease, details of intrapartum events were recorded. Demographic factors like age, socio-economic condition, educational status and obstetrical history like parity, previous mode of delivery and previous outcome of baby were recorded. Druring admission, the general condition of mothers were assessed as well as the fetal lie, presentation, position and heart sound were recorded. Pelvic examination was carried out to asses the cervical dilatation, state of liquor amni, position, presentation, pelvic assessment, degree of caput, moulding, uterine rupture. Destructive operations included craniotomy was done in dead fetus with cephalic presentation with full cervical dilation. APGAR score at 5 minutes of 7 and above was taken as normal while secores less than 7 was taken as birth asphyxia. Condition of the patient, preoperative and postoperative findings, mode of delivery, associated complication (both mother and fetus) were recorded. At post partum period data regarding maternal outcome were recorded which included abdominal distension, postpartum hemorrhage, fouel smelling discharge, fever, character of wound, burring micturiation, urinary incontinence. Fetal condition was evaluated by the nature of feeding, development of jaundice, umbilical condition, features of neonatal infection. The statistical analysis was done in SPSS version 17.

\section{Results}

The total number of 3171 deliveries was occurred during this study period of which obstructed labour was accounted for 132 cases and was given an incidence of $4.2 \%$. The highest frequency was found among the 25-30 years of age group $(21.9 \%)$ and the least frequency among those $>35$ years. The mean age was $24 \pm 5.41$ years, $46.7 \%$ case was unbooked and $52.4 \%$ had primary education only. The highest frequency (52.\%) was found among the primigararida while the least was among the multigravide (table 1).

Table 1: Socio-demographic characteristics of study population $(\mathrm{n}=105)$

\begin{tabular}{lll}
\hline $\begin{array}{l}\text { Socio-demographic } \\
\text { characteristics }\end{array}$ & Frequency & Percentage \\
\hline
\end{tabular}

\begin{tabular}{|c|c|c|}
\hline \multicolumn{3}{|l|}{ Age (years) } \\
\hline $15-19$ & 16 & 15.2 \\
\hline $20-25$ & 52 & 49.5 \\
\hline $25-30$ & 23 & 21.9 \\
\hline $30-35$ & 12 & 11.5 \\
\hline$>35$ & 2 & 1.9 \\
\hline \multicolumn{3}{|l|}{ Parity } \\
\hline 0 & 55 & 52.4 \\
\hline $1-4$ & 39 & 37.1 \\
\hline $5-8$ & 11 & 10.5 \\
\hline \multicolumn{3}{|c|}{ Educational Status } \\
\hline Illiterate & 32 & 30.5 \\
\hline Primary & 55 & 52.3 \\
\hline $\mathrm{SSC}$ & 11 & 10.6 \\
\hline HSC & 7 & 6.6 \\
\hline \multicolumn{3}{|c|}{ Occupation of Husband } \\
\hline Service holder & 24 & 22.8 \\
\hline Businessman & 15 & 14.3 \\
\hline Day labourer & 46 & 43.8 \\
\hline Farmer & 20 & 19.1 \\
\hline \multicolumn{3}{|c|}{ Socio-economic status } \\
\hline Poor & 70 & 66.7 \\
\hline Average & 28 & 26.6 \\
\hline Good & 7 & 6.7 \\
\hline \multicolumn{3}{|c|}{ Area of Residence } \\
\hline Rural & 88 & 83.8 \\
\hline Urban & 17 & 16.2 \\
\hline \multicolumn{3}{|c|}{ Antenatal check up } \\
\hline Nil & 49 & 46.7 \\
\hline Irregular & 37 & 35.2 \\
\hline Regular & 19 & 18.1 \\
\hline \multicolumn{3}{|c|}{ Duration Labour (Hours) } \\
\hline $12-24$ & 78 & 74.3 \\
\hline$>24$ & 27 & 25.7 \\
\hline \multicolumn{3}{|c|}{ Oxytocin injection given } \\
\hline Yes & 45 & 42.8 \\
\hline No & 60 & 57.2 \\
\hline
\end{tabular}


The commonest cause of obstructed labour was cephalopelvic disproportion $(44.8 \%)$ followed by malposition (persistent occipito-posterior) (25.7\%), malpresentation mostly shoulder presentation (10.5\%) and breech presentation $(9.5 \%)$. Fetal abnormality was found mostly severe hydrocephalous $(2.8 \%)$ (Table 2$)$.

Table 2: Distribution of Risk factors among obstructed labour deliveries $(n=105)$

\begin{tabular}{lcc}
\hline Risk factors & Fequency & Percentage \\
\hline Cephalopelvic disproportion & 47 & 44.8 \\
Malposition & 27 & 25.7 \\
Shoulder presentation & 11 & 10.5 \\
Breech presentation & 10 & 9.5 \\
Face presentation & 5 & 4.8 \\
Hydrocephalous & 3 & 2.8 \\
Cervical fibroid & 2 & 1.9 \\
Total & $\mathbf{1 0 5}$ & $\mathbf{1 0 0 . 0}$ \\
\hline
\end{tabular}

Majority of the patients were delivered by caesarean section $(78.1 \%)$ followed by craniotomy (16.1\%). Caesarean hystectomy was performed for $3(2.9 \%)$ cases out of which two cases for ruptured uterus, 1 case for postpartum hemorrhage. Repair of ruptured uterus was done for $3(2.9 \%)$ cases out of which 2 cases for scar rupture (Table 3 ).

Table 3 : Distribution of Mode of Delivery among the study population $(n=105)$

\begin{tabular}{lcc}
\hline Mode of delivery & Frequency & Percentage \\
\hline Lower segment caesarean section & 82 & 78.1 \\
Craniotomy & 17 & 16.1 \\
Laparotomy with repaired & & \\
ruptured uterus & 3 & 2.9 \\
Subtotal hystectomy & 3 & 2.9 \\
Total & $\mathbf{1 0 5}$ & $\mathbf{1 0 0 . 0}$ \\
\hline
\end{tabular}

Many patients had more than one complication. The most common complications was abdominal distension due to paralytic illus or peritonitis $(23.8 \%)$. Six $(5.8 \%)$ cases had ruptured uterus out of 2 had scarred uterus. One patient died due to post partum hemorrhage among 10(9.6\%) cases (Table 4).

Table 4 : Distribution of Maternal complications among obstructed labour deliveries $(\mathbf{n}=\mathbf{1 0 5})$

\begin{tabular}{lcc}
\hline Maternal Complications & Frequency & Percentage \\
\hline Abdominal distension & 25 & 23.8 \\
Puerperal sepsis & 15 & 14.3 \\
Wound infection & 13 & 12.4 \\
Post partum hemorrhage & 10 & 9.6 \\
Urinary tract infection & 6 & 5.7 \\
Ruptured uterus & 6 & 5.7 \\
Burst abdomen & 2 & 1.9 \\
Vesico vaginal fistula & 2 & 1.9 \\
Maternal death & 1 & 0.9 \\
No Complication & 25 & 23.8 \\
Total & $\mathbf{1 0 5}$ & $\mathbf{1 0 0 . 0}$ \\
\hline
\end{tabular}

Eighthly two fetus (78.1\%) were live born and 23 (21.9\%) cases were still born (Table 5).

Table 5: Distribution of fetal Condition during birth $(n=105)$

\begin{tabular}{lcc}
\hline Parameter & Frequency & Percentage \\
\hline Live birth & 82 & 78.1 \\
Still birth & 23 & 21.9 \\
Total & $\mathbf{1 0 5}$ & $\mathbf{1 0 0 . 0}$ \\
\hline
\end{tabular}

Among the live babies 35(33.3\%) cases were asphyxiated and $10(9.5 \%)$ cases developed neonatal jaundice (Table 6).

Table 6 : Distribution of fetal Complication among the live birth $(n=82)$

\begin{tabular}{lcc}
\hline Fetal Complication & Frequency & Percentage \\
\hline Asphyxia & 35 & 33.3 \\
Neonatal jaundice & 10 & 9.5 \\
Umbilical sepsis & 8 & 7.6 \\
Neonatal death & 3 & 2.8 \\
No Complications & 26 & 24.8 \\
Total & $\mathbf{8 2}$ & $\mathbf{7 8 . 0}$ \\
\hline
\end{tabular}

\section{Discussion}

In this study obstructed labour accounted for $4.2 \%$ hospital delivered within the range reported for other developed countries. In India ${ }^{19}$ its incidence was found $2.5 \%$. In Eastern Nigeria $^{20}$ study over a period of 5 years revealed the incidence was $4.7 \%$. This incidence of this study is reflective of overall health system, educational status, poverty, lake of vigilant of obstetric care, delayed referral and poor facilities for transport of patients from remote area.

Mostly obstructed labour occurred in nonbooked, primigravida, patient from rural area and those belonging to poor class, illiterate or having primary education. Health education is suggested. Specially for primigravida whose pelvis has not been tested.

Women who are educated likely to be economically and socially, empowered to break socio-culture and financial barrier. Duration of labour is the important factor that is significantly associated with maternal and perinatal mortality. In this study the most common cause of obstructed labour was cephalo-pelvic disproportion followed by malpresentation and mal-position, which was relevant to other studies $^{2,3}$. In grand multipara however malpresentation was more common than cephalo-pelvic disproportion which was statistically significant in this study.

The common mode of delivery was LUCS because of its safety. Although some still superior to LUCS in moribund cases; however studies have shown that the use of regional anesthesia has made LUCS to be safe and its outcome to be comparable to that of destructive operation in moribund cases $^{21}$. Among the destructive operation only craniotomy was done as it was easier to perform.

The risk of developing complication with either LUCS or 
destructive operation was not statistically significant which showed that either method of relieving obstruction have favorable outcome in this tertiary care centre because of advent of new generation of antibiotics, better surgical method, anesthetic facilities, good pre-operative and post operative care which has made LUCS safe. Patients before discharge were counseled to book early in subsequent pregnancies and deliver in well established health care facilities where adequate monitoring are available with facilities for caesarean section.

Regarding complications of obstructed labour abdominal distension was the most common complication followed by urinary tract infection, puerperal sepsis post partum hemorrhage. Rupture uterus is the common sequallae of obstructed labour ${ }^{22}$. In this $5.8 \%$ cases were ruptured uterus. This was due to referral of very mismanaged patient. This study has shown that uterine rupture was uncommon among the primigravida as primigravid uterus meets obstructed labour with inertia whereas multigravid uterus meets obstruction with hypertonic uterine contraction. Urinary tract infection was due to prolonged catheterization. Maternal mortality rate was about $1 \%$ in this study which is lower than that of other developing countries ${ }^{1-10}$ because of meticulous care. In this study maternal death occurred due to extensive rupture.

Vesico-vaginal fistula is a well known late squeal of obstructed labour superscript ${ }^{23}$. In this study VVP was developed $1.9 \%$ cases. The poor fetal outcome with perinatal mortality and morbidity was $52.2 \%$ because of prolonged labour, neonatal sepsis from multiple unsterile vaginal examination before attended 10 hospitals which is similar to other studies ${ }^{23-24}$. Obstructed labour can be prevented by providing optimal obstetric care, good nutritional support as nutrition is essential for normal pelvis ${ }^{3}$; however it takes long time to attain the goal. Another important potential intervention for prevention of obstructed labour was antenatal care coverage. In this study overall antenatal coverage was $18.1 \%$.

The strength of this study is that a proper predesigned questionnaires has been made for collecting data, better surgical method, good pre-operative and post operative care. Information regarding the duration of labour was not satisfactory as labour at home and attended by untrained dais.

In the absence of sophisticated fetal and maternal monitoring devices cases were evaluated clinically. The uterine activity measurement was not possible and assessment of severity of fetal distress sometimes was not accurate.

\section{Conclusion}

In this study the commonest cause of obstructed labour is the cephalopelvic disproportion, malposition and malpresentation of which shoulder presentation \& breech presentation are the most common. Severe hydrocephalous is the most common fetal abnormality found in this study. To decrease these unfortunate and mostly preventable obstetrics complications, restructuring to $\mathrm{MCH}$ service should be done with particular attention to increase the community awareness, decentralization to maternity service, effective health care and effective referral system.

\section{References}

1. Gayam A. Obstructed labour at a district hospital. Ethiop Med J. 2002;5(2):37-40

2. Philpott RH. Obstructed labour Clinics in Obstetric and Gynecology. 1982;9(3): 625-640

3. Konje JC, Ladipo OA Nutrition and obstructed labour. Am Jclin Nutr, 2000; 72(1): 291-297

4. Daffallah SE, Ambago J, E1- Agib F. Obstructed labour in a teaching hospital in sudan. Saudi Med. J. 2003; 24: 1102-1104

5. Karis A, Dasgupta M, Sanghamita M. Management of obstructed labour: a retrospective study. J Obstet Gynaecol Ind 2005; 55(1): 48-51

6. Wall LL. Dead mothers and injured wives; The social context of materral mortllity and morbidity among the Mausa of Northern Nigeria. Stud Fam Plan, 1998; 29: 341-359

7. Emergency obstetric care: Interventions for the reduction of maternal mortality, obstetrical and Gynaecological society of Bangladesh and UNICEF, 1993; p.2-13

8. Rush D. Nutrition and maternal mortality in the developing world. AMJ Clin Nutr, 2000; 72: 212-240

9. Khan S. Obstructed labour: The preventable factor. J Pak Med Assoc. 1995; 45: 261-263

10. Bhaskar Rao K. Current practice of obstetrics and Gynaecology. The Federation of Obstetridx and Gynaecology, India. 1992; 132

11. Kunji JC, Ladipo OA. Nutrition and Obstructed labour. Am J Clin Nutri, 2000; 72 (1): 2915-2975

12. Moller B, Mark LG. Short stature: an obstetric risk factor? A comparison of two village in Tazania Acta. Obstet Gynaecol Scand 1997; 76: 394-397

13. Bhuiyan A. B. The community midwives (Editional), Bangladesh Journal of Obstet and Gynaecol, 1977; 12: 36-40

14. Omole- ononsi A, Mohammand Z. caesarean section in kano, Northern Nigeria. Nig. Clinical Review. 2005;12(6):4-6

15. Gessessew A, Mesfin M. Genitourinary and rectovoginal fistula in Adigrat Hospital, Tigrag, Ethiopia. Proceeding of XIII th Annual Public Health Conference, 2002

16. Population Action International How access to sexual and reproductive health service is key to the MDGS. Fact sheet 31 in serious population Action international, Washington, 2005

17. Khan AR. Jahan FA, Begum SF. Maternal mortality in rural Bangladesh. Jamalpur district Stual Fam Plan. 1986; 17(1):13-21

18. WHO. The world, Health Report in make every mother and child court world Health Organization, Geneva, 2005

19. Kwast B. E. Obstructed labour, Its contribution to maternal mortality. Midwifery. 1992; 8CD: 3-7

20. Ozumba BC. Uchegbuth. Incidence and management of obstructed labour in Estern Nigeria, Obstet Gynanaecol. 1991;31(3):213

21. Biswas A, chak raborty ps, Das HS, etal. Rote of destructive opretation in modern day obstetrics. J Indian Med Assoc, 2001; 99(5):248 22. A boyej AP. Ijaija MD. Yahaya UR. Rupture Uterus: a study of 100 consecutive cases in Nigeria. J Obstet Gynaecol Res, 2001;27(6):341

23. Danso KA, Martey JO, Wall LL, Elkins TE. The epidemiology of genitourinary fistulae in Kumasi, Ghana, 1977-1992. International Urogynecology J 1996;7(3):117-120

24. National Clinical service protocol for obstetric and Neonatal care. FMOH Nigeria. 2006; 317

25. Naeye RL, Dozor A, Tafari N, Ross SM. Epidemiological features of perinatal death due to obstructed labour in Addis Ababa. BJOG: An International J Obstet Gynaecol 1977;84(10):747-750 